\title{
Dynamic Assessment (DA): An Evolution of the Current Trends in Language Testing and Assessment
}

\author{
Parviz Birjandi \\ Islamic Azad University, Science and Research Branch, Tehran, Iran \\ Email: pbirjandi@yahoo.com \\ Saeid Najafi Sarem (Corresponding author) \\ Islamic Azad University, Science and Research Branch, Tehran, Iran \\ Email: s_najafisarem@yahoo.com
}

\begin{abstract}
Traditional static testing, aimed at measuring the achievement of pre-determined criteria, has been widely used by language teachers for many years. Such tests conventionally reflected students' misunderstanding of instruction more than their abilities to perform a task. Disillusionment with traditional assessment has led to an examination of alternative assessment procedures that are accurate and appropriate in evaluating diverse populations' learning. Dynamic Assessment (DA) stems from the mutually constitutive relationships between methodology and epistemology. Its root is the concept of development in Vygotsky's Zone of Proximal Development (ZPD). The central feature of DA is that it does not separate instruction from assessment, but instead, is in favor of a teacher-student unity that works jointly towards students' future improvement through their ZPD. The present article is a literature review which aim to look critically at the emergence of DA as an alternative approach to the previous traditional approaches. Also, after taking a look at the theoretical framework as well as different models of DA, the researcher goes on to discuss the merits and demerits as well as the application and implication of DA in the scope of language teaching and language testing.
\end{abstract}

Index Terms - Dynamic Assessment (DA), models of DA, theoretical framework of DA

\section{INTRODUCTION}

Testing as a universal feature of social life has attracted a great deal of attention by many language teachers and scholars. Throughout history people have been put to the test to prove their capabilities or to establish their credentials. According to McNamara (2000) Language tests play a powerful role in many people's lives, acting as gateways at important transitional moments in education, in employment, and in moving from one country to another. Since language tests are devices for the institutional control of individuals, it is clearly important that they should be understood, and subjected to scrutiny. Therefore, an understanding of language testing is relevant both for those actually involved in creating language tests, and also more generally for those involved in using tests or the information they provide, in practical and research contexts (McNamara, 2000).

One of the areas in which language testing is of great application and has great implications is language teaching. From the early days of language teaching, language tests have been always utilized by teachers as important devices for the purposes of assessment, evaluation as well as many other applicable purposes related to both the process of language teaching and language learners themselves. The emergence of new approaches, theories and methods in language teaching has affected the form and type of language tests too. In fact, theoretical developments in the area of language teaching have been compatible with that of language testing. Kuhn's (1962) concepts of paradigm and paradigm shift help understand the issue well. It simply states that the appearance of a new paradigm in a specific point in time has influenced all the previous teaching and testing practices and thus has led to the shift in the ruling paradigm as well as introduction of new notions compatible with the latest scientific achievements. Taking a glance at the early days of language teaching reveals that when the aim of language learning was the ability to read the target literature, language tests usually consisted of essay writing, translation and grammatical analysis judged subjectively by language teachers. Considering the evolutionary path of language teaching as a long continuum, at one end, as it was mentioned above, there was Grammar Translation Method (GTM) in congruity with teachers' biased judgments, while at the other end there is Communicative Language Teaching (CLT) moving away from psychometric and discrete-point testing and focusing on dynamic ways of assessment which integrate both teaching and testing together. This evolutionary movement in the area of language testing, indeed, can be regarded as a revolution which opened up new insights both for language teachers as well as language learners. Therefore, the present article, through an elaborate literature, starts with an introduction to the history of language testing, and then goes on to present a critical look at the emergence of 
Dynamic Assessment, its theoretical framework, its models, merits and demerits as well as its application and implication in the scope of language teaching as well as language testing.

\section{The History of LANGUAGE Testing}

As it was aforementioned, along with the theoretical advancements in the domain of language teaching, language tests themselves have undergone certain changes based on the scientific shifts dominant in the field. As Weir (1993) states language tests from the distant past to the present are important historical documents. They can help inform us about attitudes to language, language testing and language teaching when little alternative evidence of what went on in the bygone language classroom remains. Seeing where we have come from also helps us better understand where we are today. This line of different language testing can be categorized as follows:

\section{A. Traditional Essay Translation Approach (1930s)}

This approach was commonly referred to as the pre-scientific stage of language testing. During this period of language testing, no specific skill or expertise in testing was required. The subjective judgment of the teacher was considered to be of paramount importance. Essay writing, translation and grammatical analysis were the most common types of tests in this period. Tests had a heavy literary or cultural bias. During this period, formal language testing involved the assembly of recognized language experts in the development of the test. Based on the involvement of experts, the test maker claimed the test to be valid and reliable (Spolsky, 1978). Grammar translation method was the offspring of the traditional approach in linguistic analysis which concerned itself with a very shallow, surface analysis of language.

\section{B. Structuralist Approach (Discrete-point) (1960s)}

Baker (1989) mentioned that the roots of this approach can be traced back to the traditions of Psychometric Testing and Structural Linguistics. The psychometric tradition in psychology provided the tools for producing and developing tests which were mostly of "closed" type. Also, a fairly elaborate system of statistical procedures had been evolved for developing and evaluating this kind of test. Based on structural linguistics, the basis for the content of the tests was provided. Therefore, tests developed in this era were designed to focus on measuring sounds, words and structures in isolation and mostly in a decontextualized format. Since the items focused on discrete elements of language, the focus was on the linguistic content of items, and the items were often placed outside of a communicative context, this came to be known as discrete point testing. Weir (1990) maintained that the clear advantages of testing "discrete" linguistic points are that they yield data which are easily quantifiable, as well as allowing a wide coverage of items. According to Oller (1979) this approach suffered from some deficiencies. Discrete point analysis necessarily breaks the elements of language apart and tries to teach them or test them separately with little or no attention to the way those elements interact in a large context or communication. What makes it ineffective as a basis for teaching or testing languages is that crucial properties of language are lost when its elements are separated.

\section{The Integrative Approach (1970s)}

Spolsky (1978) called the third stage the 'integrative-sociolinguistic stage,' and it became prominent during the seventies. The decade of the seventies saw a more intense use of statistics to examine tests. In that sense, the 1970s was notably more scientific (psychometric) than the 1960s. This approach involved the testing of language in context and was thus primarily concerned with meaning and the total communicative effect of discourse. These tests were often designed to assess the learners' ability to use two or more skills simultaneously. Thus, integrative tests were concerned with a global view of proficiency-an underlying language competence or grammar of expectancy, which every learner possessed regardless of the purpose for which the language is being learned.

Integrative testing involves functional language but not the use of functional language. Integrative tests are best described by the use of cloze testing and of dictation. The rational for integrative testing is derived from the transformational linguist's concentration on language competence and the cognitive psychologist's rationalistic approach in trying to discover the psychological principles of organizing and functioning.

John Oller wrote extensively during this period, so much so that one could call this "the decade of John Oller". Oller's (1976) approach differed from the approach of the 1960s in that he focused on the test as a whole, and attempted to define the construct that it measured. The first feature of the psychometric approach which Oller challenged was the neglect of context. Oller's proficiency was unitary; where discrete-point tests eliminated context.

Some experts believe that integrative and discrete-point tests form the two extremes of one continuum. On the one hand, there are the most discrete-point items, on the other there are the most integrative with most types of items such as reading comprehension items falling in between.

\section{Functional-communicative Approach (1980s)}

Publishing an article with the title 'Theoretical bases of communicative approaches to second language teaching and testing', Canale and Swain (1980) can be considered as the originators of this approach to language testing. Canale and Swain (1980) proposed a tripartite theory of communicative competence consisting of grammatical competence, sociolinguistic competence, and strategic competence. They discussed the relevance of these different types of 
competence for second language teaching and second language testing. Within the realm of testing, they discussed the features of competence that could go into a communicative test and the features of the examinee's performance that could or should be evaluated. Their framework made continual reference to the communicative context and the learner's communication needs.

Communicative tests are concerned primarily with how language is use in communication. Because of their emphasis on context and authentic material they reflect the culture of a particular country. Since they take the learners' needs into account, they are very much suitable for the testing of English for specific purposes. Communicative testing has introduced the concept of qualitative modes of assessment in preference to quantitative ones. This approach is advantageous over the previous approaches in that it adopts a more humanistic approach to language testing. The functional-communicative approach has moved away from norm-referenced testing and prefers to make use of criterion-referenced testing, that is, each student's performance is evaluated according to his or her degree of success in performing the language tasks rather than solely in relation to the performances of other students. Moreover, from another point of view, qualitative forms of assessments are given preference and superior to quantitative assessments favored in psychometric testing.

It should be kept in mind that, in most cases, the difference between various theories is not of type but of degree. In fact, all tests can be placed along a continuum with more discrete-point items at the one end and more functional items at the other.

\section{Changes of Scope And Philosophy: From Testing to Assessment}

As was mentioned above, for nearly half of a century, various forms of language tests with different aims dominated the field of language testing and teaching. Most of such tests consisted of large-scale tests with strong emphasis on statistical analysis. Tests' scores were considered as the only true indicator of testees' performances without any attention to the process of learning and teaching. School practices remained in fact largely conditioned by the traditional vision of assessment characterized by tests, examinations, selection, grades and marks. However, there was a strong need for language testers to rethink their assumptions about language testing and consider tests as a fruitful activity yielding significant results concerning both the processes of teaching and learning.

Assessment developed historically for the purposes of selection and certification - particularly, selection for further educational opportunities beyond the minimum state provision and for employment (Torrance, 1995). The pressing need to find a mechanism of selection that would be socially acceptable and would identify the 'best' candidates led to a premium being put on assessment techniques that appeared to be fair and objective, and had high levels of reliability (Broadfoot, 1995). According to Torrance (1995) assessment experts have for the past couple of decades recognized and argued in favour of assessment as an essential component to learning. This theoretical shift away from 'measuring' learning and towards assessment that is explicitly designed to promote learning came primarily in response to our growing understanding of learning as a meaning-making process in which, contrary to our prior understanding that knowledge can be passed directly from one head to another, much depends on the learner's constructions of his or her own experiences. Another contributing factor was the realization of the multiple ways in which the still ubiquitous presence of the traditional forms of assessment - namely, tests and examinations - in contemporary educational systems affects negatively the teaching-learning environment.

In spite of the public acceptance, Gipps (1994) contends that the fact remains, however, that the traditional assessment model hinders learning in multiple ways. The very essence of traditional assessment, especially within the confines of the classroom, rejects the foundations of a quality education that would ultimately benefit both individuals and society at large. If we widen our understanding of the fact that everyone has the capacity to learn and is worthy of the best possible investment in his or her education - it becomes unsustainable to continue using an assessment model that has traditionally developed to focus on selection, certification and accountability. In particular, it is recognized that assessment is now required to achieve a wider range of purposes which includes supporting teaching and learning, providing information about students, teachers and schools, and driving the curriculum and teaching. This fact has increasingly rendered the traditional model underpinning assessment theory an inadequate framework and has necessitated the development of a new theory to further our understandings of, and practices in, educational assessment (Gipps, 1994). This new reconceptualization of assessment, which is educationally promising, will be discussed through the following sections.

\section{What IS DyNAMiC ASSESSMENT (DA)?}

As it was mentioned through the lines above, for a couple of years traditional forms of assessment were dominant in the field of language testing. According to Garb (2008, cited in Xiaoxiao \& Yan, 2010) traditional summative assessment attempts to summarize students' learning at some point in time, say the end of a course, but cannot provide the immediate, contextualized feedback useful for helping teacher and students during the learning process. He describes DA as a way of assessing the true potential of children that extends the interactive nature of leaning to the process of assessment. The teacher and the students come into a dialogue to find out the students' current level of performance on any task and share with each other the possible ways in which that performance might be improved on 
a subsequent occasion. This deliberate and planned meditational teaching and the assessment becomes an integral and continuous process. In DA the teacher acts as an improvement promoter and provides immediate and situated feedback during the whole procedure; moreover, the focus of DA is students' future development, not the outcome of the past development (Garb, 2008, cited in Xiaoxiao \& Yan, 2010).

Moreover, as Lidz (1978, p. 99) state DA challenges conventional views on teaching and assessment by arguing that these should not be seen as separate activities but should instead be fully integrated. This integration occurs as intervention is embedded within the assessment procedure in order to interpret individuals' abilities and lead them to higher levels of functioning. The unification of assessment and instruction is grounded in Vygotsky's understanding of development.

According to Haywood and Lidz (2007, p. 1) the dynamic assessment website defines DA as "an interactive approach to conducting assessment within the domains of psychology, speech/language, or education that focuses on the ability of the learner to respond to intervention." They maintain that what is the major component of definitions provided so far for DA is "active intervention by examiners and assessment of examinee's response to intervention." (p. 1)

Haywood and Tzuriel (2002, cited in Haywood \& Lidz, 2007, p. 2) define dynamic assessment as "a subset of interactive assessment that includes deliberate and planned meditational teaching and the assessment of the effects of that teaching on subsequent performance."

\section{THEORETICAL BASIS OF DA}

The theoretical roots of DA lie in Vygotsky's socio-cultural theory of child development, (Vygotsky, 1986) in which the role of the parent, carer, teacher, sibling, or peer, in interacting with the individual child, is seen as fundamental to the formation and growth of cognitive skills, which are culturally mediated through these interactions. Cultural mediation is essential in the development of intelligence. For cognition development, sociocultural theory argues that the unit of analysis for the study of development is not the individual acting alone, but the interpersonal functional system formed by people and cultural artifacts acting jointly. As Wu (2006, cited in Xiaoxiao \& Yan, 2010) states according to the sociocultural theory, human learning is mediated leaning. Through mediation, usually in the form of dialogue, human cognition develops from other-regulation (the assistance from other significant people, for example a teacher) to self-regulation (independent completion of a given task).

One of the key branches and constructs of Vygotsky's (1986) sociocultural theory is the Zone of Proximal Development (ZPD). The ZPD is defined as the extent to which a child can perform with assistance what they cannot perform alone. In ZPD, the whole picture of learners' development not only includes their actual level of development, but also their responsiveness to mediation which can provide insight into their future development. Vygotsky's (1978) conceptualization of a zone of proximal development (ZPD) suggested that learning can be greatly facilitated in interactions between students and a more knowledgeable and experienced person. Furthermore, students develop the mental functioning required in social interaction within ZPD (Brown, 2004).

Although DA is based on the theory of ZPD originated from Vygotsky's socio-cultural approach, it has not been used by Vygotsky himself. In fact, it is a notable contribution of Feuerstein's work. As Xiaoxiao and Yan (2010) state, Feuerstein regarded DA as a way of assessing the true potential of children that differs significantly from conventional tests. DA is an interactive approach to psychological assessment that embeds intervention within the assessment procedure. According to Xiaoxiao and Yan (2010) the most important two characteristics of DA are: 1) inseparability of assessment and instruction, 2) construction of future development. Thus in fact DA is a future-in-the-making model where assessment and instruction are dialectically integrated as the means to move towards an always emergent future rather than a fixed end-point.

Pena et al. (2001) mentions that the mediated learning experience (MLE) is designed to teach the child problemsolving strategies to achieve successful test-taking performance. The four mediation components include intentionality, transcendence, meaning, and competence. The mediator intends to teach (intentionality), and he/she links the immediate task to events in the child's experience (transcendence). The mediator enhances the child's awareness of why the task is relevant (meaning). Finally, helping the child carry out strategies for approaching a task fosters competence (Lidz, 1991; Pena et al., 2001).

Seen in its theoretical context, DA is a broad approach, not a set of specific tests. The psychologist's goal is one of identifying what cognitive skills need developing and strengthening in a child (and this can be conveyed, for example, in the format of an Individual Education Plan), the cognitive requirements of given types of task (which can inform differentiation of the curriculum for the child) and advising upon and supporting the teaching of the child. This will be direct teaching of cognitive skills, as well as of traditional curriculum content. This micro-analysis focuses on the three 'partners in the learning process': the child, the task and the mediator (typically parents or teachers). DA aims to help optimize, through understanding the interplay of these essential elements, the match between the learner and the curriculum on offer (Stringer et al., 1997).

\section{MODELS OF DA}


There are different models of dynamic assessment based on which the nature of the assessment procedure varies between these models. A typical DA procedure may involve three phases, a pre-test, teaching, and post-test, in which interaction takes place in the teaching or learning phase. Jitendra and Kameenui (1993) have proposed five models of DA each one will be discussed briefly below.

The fist model is the test-train-test assessment, which is based on a psychometric model of assessment developed by Budoff in 1974. This procedure, they explained, yields a post-test score which is an individual's "optimal" level of performance; this can be utilized to plan instruction based on an individual's cognitive strength.

The second model examined is Feuerstein's (1979) Learning Potential Assessment Device: Meditational Assessment, which is based on a theory that a lack of mediated learning experiences (interaction between a human and an experience) results in cognitive deficiencies. An advantage of this model is that it allows an examiner to frame or select environmental experiences in a way as appropriate learning sets and habitats for the learner (Feuerstein, 1979).

The third model examined is the Testing-the Limits Assessment approach; this is based on the idea that intraindividual differences in processing information occur because of intellectual and personality factors. Jitendra and Kameenui (1993) pointed out that this approach has the advantage of incorporating the testing procedure or interventions directly into the test situation. In addition, these authors specified that procedures incorporated may vary and lead to higher levels of performance irrespective of level of intelligence, cultural or racial differences, or whether a student has a learning disability. Another advantage involves modifications embedded in the testing conditions. In other words, this approach does not require changes in the arrangement or content of traditional tests.

The fourth model examined is the Graduated Prompting Assessment Approach. An advantage here is that it utilizes a graduated prompting process and the ZPD to predict student's readiness to learn or benefit from instruction, and does not rely on making high-level inferences. A benefit of this gradation of prompts is that it yields a measurement of the minimum amount of assistance necessary to problem-solve a task; this in turn helps evaluate the student's learning or transfer efficiency.

The fifth model examined is A Continuum of Assessment Model-Mediated and Graduated Prompting, which includes mediation assessment that results in a brief, scripted instructional procedure and graduated prompting assessment. This DA model provides valuable information about learning. Another value of this model is its mediated assessment scripts, which can be used to bypass the difficulties encountered with training procedures and high-level inference; its static measures can also be used in conjunction with graduated prompting procedures. Students who perform below criterion can be provided with mediation dynamic assessment to increase independent task performance on tasks already taught. Other benefits of this procedure include generalization to a transfer task with the graduated prompting method, and greater generalization with the mediation (Jitendra \& Kameenieu, 1993).

\section{CONCLUDING REMARKS}

As it was discussed through this paper, conventional static language tests dominated the field of language testing for many years. The central purpose of such tests was to determine whether some pre-determined achievement level had been reached. Traditional static assessment was limited because it did not directly aim to stimulate learners into becoming independent knowledge constructors and problem solvers. In reaction to traditional language testing there was increasing interest in Dynamic Assessment (DA), which saw language learning as knowledge construction and as being the outcome of an interaction between students and teachers. This approach derived from Vygotsky's (1986, 1978) concept of ZPD-- the idea on how child's cognition develops. Dynamic Assessment (DA) posited that learners' potential is a reliable measure for predicting learners' possible improvement in future, that is, learners' responsiveness to instruction was seen as a measure of learners' potential (ZPD).

Dynamic assessment is recommended as a valid and useful assessment approach which could serve maximized instruction across age groups (Banks \& Neisworth, 1995). When working with diverse populations, practitioners can utilize DA, which focuses on the learning process and utilizes meditational approaches that are more closely related to learning process in school and other life contexts (Haywood \& Lidz, 2007). Dynamic assessment, though still in the developmental stages, shows strong potential as a language evaluation approach for distinguishing differences from disorders in minority children (Ukrainetz et al., 2000). This alternative assessment provides a solution to the traditional problems of cultural insensitivity inherent in normed tests, and is used to describe psycho-educational assessment procedures (not specific tests or instruments) characterized by a sequence of testing, including pretesting, teaching, and post-testing (Banks \& Neisworth, 1995).

Moreover, with regard to the characteristics of DA as well as its utility for diverse learners, some implications can be drawn for its practitioners. First of all, standardized test scores can still be reported, because test administration is not modified, and the student's increase in test scores (as well as their test scores following teaching) may be considered as important as initial test results (Pena et al., 2001). Secondly, DA provides more valid measures of ability. Thirdly, mediated learning experience helps children understand the test tasks with which linguistically-diverse learners are unfamiliar. These students become more aware of labels and the need to use labeling in their daily activities. When they learn linguistic strategies, they can transfer mediated skills across tasks. Therefore, mediated learning experience reduces test bias and improves standardized scores (Pena et al., 2001; Pena et al., 2006). Fourthly, dynamic assessment not only indicates possible educational placement for linguistically-diverse learners, but also suggests effective 
directions for instructions (Lidz \& Pena, 1996). Finally, dynamic assessment is a multidimensional assessment procedure that can be used across disciplines (e.g., educators, speech and language pathologists), settings (e.g., school, home, and community), and diverse populations (Banks \& Neisworth, 1995).

Every new paradigm and theory, concerning its applications and implications has some advantages and disadvantages. Considering the merits of DA, it has been suggested that DA may be especially useful in assessing bilingual children, as well as those from a variety of cultural and ethnic backgrounds (Usmani, 1999). Indeed, in a number of situations, including disability and disadvantage, in which individual functioning poses challenges to school provision, DA is intuitively appealing as educational psychologists search for approaches that seek to explore learning potential rather than confirm poor current performance (Usmani, 1999).

On the other hand, considering its demerits, it should be mentioned that the field of DA as a whole still lacks a substantial body of empirical studies. What has been presented so far is a body of literature trying to elucidate the theoretical foundations and concepts of DA; however, not many practical investigations have been done in the area of language teaching and testing. Adequate training and support would seem to be essential if educational psychologists are to have a real choice of approaches to assessment and, in particular, if DA is to be critically evaluated. In fact, as a newly emergent instruction pedagogy grown up from a well-developed set of theories, DA is not yet widely practiced and is still virtually unknown to many psychologists and educators. According to Thorne (2005, p. 399), DA, a procedure that "unites the goals of better understanding a learners' potential through structured sets of interactions and fostering development through those interactions, is just emergent into social-cultural-based L2 language research" (Cited in Xiaoxiao \& Yan, 2010). Except for quite few preliminary DA theory introduction (Tang, 2004), discussion of the strategies for how to practice DA (Peng Jinding, 2004) and the prospect of application of DA in general education and special education (Wang \& An, 2005), no practical experimental application has been mentioned in foreign language teaching classroom (Cited in Xiaoxiao \& Yan, 2010).

On the whole, we can affirm that the paradigm of dynamic assessment is useful not only in the field of general cognitive performance but also in such curricular domain as EFL learning. At the same time one should be aware of those characteristic features of the dynamic assessment procedure that impose certain limitations on the generalizability of the results. Any dynamic assessment that includes an element of intervention depends on the quality of mediation provided by the assessor. In this respect dynamic assessment is closer to a situation of instruction rather than examination.

\section{REFERENCES}

[1] Baker, D. (1989). Language testing: A critical survey and practical guide. London: Edward Arnold

[2] Banks, S. R., \& Neisworth, J. T. (1995). Dynamic assessment in early intervention implication for serving American Indian/Alaska native families. Journal of American Indian Education, 34(2), 27-43.

[3] Broadfoot, P. (1995). Performance assessment in perspective: International trends and current English experience. In H. Torrance (Ed.), Evaluating authentic assessment: Problems and possibilities in new approaches to assessment (p. 9-43). Buckingham: Open University Press.

[4] Canale, M. \& Swain, M. (1980). Theoretical bases of communicative approaches to second language teaching and testing. Applied linguistics, 1, 1-47. Doi:10.1093/applin/1.1.1.

[5] Feuerstein, R. (1979). The dynamic assessment of retarded performers: The learning potential assessment device, theory, instruments, and techniques. Baltimore: University Park Press.

[6] Gipps, C. (1994). Beyond testing: Towards a theory of educational assessment. London: Falmer Press.

[7] Haywood, H. C., \& Lidz, C. S. (2007). Dynamic assessment in practice: Clinical and educational applications. Cambridge, UK: Cambridge University Press.

[8] Jitendra, A. K., \& Kameenui, E. J. (1993). Dynamic assessment as a compensatory assessment approach: A description and analysis. Remedial and Special Education, 14(5), 6-18. Doi: 10.1177/074193259301400503.

[9] Kuhn. T. (1962).The structure of scientific revolutions. Chicago: University of Chicago.

[10] Lidz, C. (1987). Dynamic assessment: An interactional approach to evaluating learning potential. New York/London: Guildford Press.

[11] Lidz, C. (1991). Practitioners guide to dynamic assessment. New York/London: Guildford Press.

[12] Lidz, C.S., \& Pena, E. D. (1996). Dynamic assessment: The model, its relevance as a nonbiased approach, and its application to Latino American preschool children. Language, Speech, and Hearing Services in Schools, 27, 367-372.

[13] McNamara, T. (2000). Language testing. Oxford: Oxford University Press.

[14] Oller, J. W. (1976). Language testing. In R. Wardhaugh, \& H.D. Brown (eds.), A survey of applied linguistics. Ann Arbor: University of Michigan Press.

[15] Oller, J. W. (1979). Language tests at school. London: Longman

[16] Pena, E., lglesias, A., \& Lidz, C. S. (2001). Reducing test bias through dynamic assessment of children's word learning ability. American Journal of Speech-Language Pathology, 10,138-154.

[17] Pena, E. D., Gillam, R. B., Malek, M., Ruiz-Felter, R., Resendiz, M., Fiestas, C., \& Sabel, T. (2006). Dynamic assessment of school-age children's narrative ability: An experimental investigation of classification accuracy. Journal of Speech, Language, and Hearing Research, 49, 1037-1057.

[18] Spolsky, B. (1978). Introduction: Linguists and language testers. In B. Spolsky (ed.), Approaches to language testing: Advances in language testing series 2. Arlington, VA: Center for Applied Linguistics. 
[19] Stringer, P., Elliot, J. \& Lauchlan, F. (1997). Dynamic assessment and its potential for educational psychologists Part 2: The zone of next development? Educational Psychology in Practice, 12(4), 234-239. doi.org/10.1080/0266736970120409.

[20] Torrance, H. (1995). The role of assessment in educational reform. In H. Torrance (Ed.), Evaluating authentic assessment: Problems and possibilities in new approaches to assessment (pp. 144-156). Buckingham: Open University Press.

[21] Ukrainetz, T. A., Harpell, S., Walsh, C., \& Loyle, C. (2000). A preliminary investigation of dynamic assessment with native American kindergartners. Language, Speech, and Hearing Services in Schools, 31, 142-154.

[22] Usmani, K. (1999). The influence of racism and cultural bias in the assessment of bilingual children. Educational and Child Psychology, 16 (3), 44-54. Doi:10.1080/0266736970120409.

[23] Vygotsky, L. S. (1986). Thought and language. Cambridge, MA: MIT Press.

[24] Vygotsky, L. S. (1978). Mind in society. Cambridge, MA: Harvard University Press.

[25] Weir, C. J. (1990). Communicative language testing. New York: Prentice-Hall.

[26] Weir, C. J. (1993). Understanding and developing language tests. New York: Prentice-Hall.

[27] Xiaoxiao, L., \& Yan, L. (2010). A case study of dynamic assessment in EFL process writing. Chinese Journal of Applied Linguistics, 33 (1), 24-40.

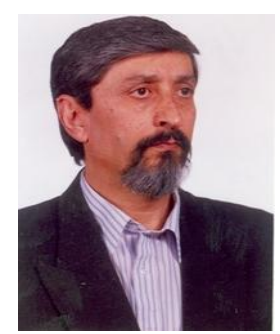

Parviz Birjandi is a full professor of TEFL. He is holding an M.A in applied linguistics from the Colorado State University and a Ph.D. in English education; minor: Research methods and statistics from the University of Colorado. He has got his B.A. from Tehran University in the 1970s. He has established TEFL in many Iranian universities in his long effective career. Dr. Birjandi established the first curriculum for Ph.D. in TEFL at the Iranian Islamic Azad University, Science and Research Branch for the first time and after that in Allameh Tabataba'i University and Tehran University. Many Iranian Ph.D. holders of TEFL and hundreds of M.A. holders have been his students in different Iranian universities. He is considered as "the Founder of Iranian TEFL" by many university professors and educational experts in Iran and some conferences has been held on his honor in different parts of the country. He is currently the Dean of the College of Foreign Languages and Persian Literature in the Islamic Azad University, Science and Research Branch. He has published more than 40 articles in the area of TEFL and he is the author of English textbooks for high school and pre-university levels, used nationwide, more than 10 university textbooks and many practice textbooks. Dr. Birjandi is also well-known for his warmth and respect as well as empathy toward his students.

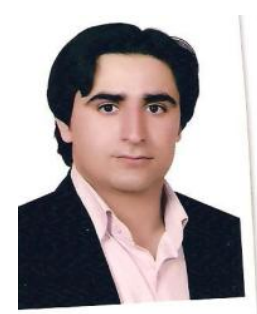

Saeid Najafi Sarem is a Ph.D student of TEFL in Islamic Azad University, Science and Research branch, Tehran, Iran. He is the head of Sharif Language Institute in Asadabad, Hamedan, and he is currently teaching in Azad and Payamnoor universities in Hamedan. He is interested in teaching methodology and second language acquisition (SLA) studies and has presented many articles in different national and international conferences. He has got some publications in different national and international journals as well. 